\title{
Illness and Treatment among Khonds of Visakhapatnam District, Andhra Pradesh
}

\author{
V.L.N. Rao, B. Dharma Rao, Ch. Seshagiri Rao, K. Bharathi and B.R. Busi
}

Department of Anthropology, Andhra University, Visakhapatnam 5300 03, Andhra Pradesh, India E-mail: Vithala_narasimha rao2000@yahoo.com

\author{
KEYWORDS Health. Diseases. Treatment. Tribes
}

\begin{abstract}
Khond subjects drawn randomly from 18 villages of Chintapalli, G. Madugula and Pedabayalu mandals of Visakhapatnam district, Andhra Pradesh (during April - October 2004) were examined for the frequency of respiratory, air born, infective and waterborne diseases, injuries and accidents and poisoning due to animal bites. The frequency of scabies, malaria, cholera, diarrhea and vomiting is observed to be higher when compared to other diseases. Majority of the subjects were observed to show preference towards the use of indigenous method of treatment when compared to modern method of treatment. The data collected on the epidemiological status among Khonds will help to suggest suitable programmes and strategies for improvement of the health status of this vulnerable group.
\end{abstract}

Health is a state of complete physical, mental and social well-being and not merely the absence of disease and infirmity (WHO, 1946). There are three main factors, which determine the health condition of a person such as genetics, environment and Life styles (Smith, 1992). Environment refers to aspects such as housing, availability of potable water, healthy air etc. and life styles include smoking, eating, drinking etc. The environment has a major influence on life style and life style can modify the effects of the environment. Poor health status reflected in tribal health care practices is the outcome of their ecological, social and living conditions, illiteracy, ignorance, under availability of potable water etc., and inappropriate medical and health opportunities. There is a general agreement that health status of the tribal populations in India is very poor. Different studies (Basu, 1986, 1990; Chowdhuri, 1986; Rizvi, 1990; Mahapatra et al., 1990 and Swain et al., 1990) have tried to establish this with the help of morbidity, mortality and health statistics. The widespread poverty, illiteracy, malnutrition, absence of safe drinking water, sanitary and living conditions, poor maternal and child health services, ineffective coverage of national health and nutritional services, have been traced out in several studies as possible contributing factors for dismal health conditions prevailing among these vulnerable populations (Bhasin, 1990). Safe water and sanitation are the two basic components of hygiene, which have a strong cultural determination and key influence on people's health perhaps comparable only to food. Only $31 \%$ of rural India has easy access to safe water and only $2 \%$ has any access to sanitation facilities (Bhasin, 1994). Very few studies were conducted on the health status of tribal populations of North coastal Andhra Pradesh and adjoining Orissa such as on Jatapu, Gadaba and Manne Dora of Vijayanagaram district, Andhra Pradesh (Raj Pramukh, 1998), Savaras of Rayagada district, Orissa (Behura, 2003) and on ethno-medical practitioners among Khonds of Orissa (Maghi and Sharma, 2004)

The present study is carried out on 'Khond', a Primitive tribal population of Andhra Pradesh. According to the 1991 census, the Scheduled tribal population of India is 67.76 million constituting $8.08 \%$ of the total population. The Scheduled tribal population of Andhra pradesh is estimated as 4.2 million and Visakhapatnam district having 4.69 lakhs of Scheduled Tribes (S.T) population. There are 75 Primitive Tribal Groups (P.T.G) out of 650 scheduled tribal populations in India and Andhra Pradesh includes 13 such Primitive tribal groups.

\section{MATERIAL AND METHODS}

Khond is one of the Primitive tribal groups found predominantly in the agency tracts of Visakhapatnam district, Andhra Pradesh. They are called Kodulu or Samanthulu in the agency tracts of Visakhapatnam district. They mainly depend on Podu cultivation.The population of Khond in the ITDA (Paderu) sub-plan area is reported to be 51,293 (1998). They are divided into four sub-tribes viz., Jatapu Khond, Desai Khond, 
Dungria Khond and Kutia Khond. The present investigation is conducted on Kutia Khond. They are further divided into a number of totemic clans. The data were collected through household interview schedule. 18 villages were randomly selected from the three sample mandals i.e., Chintapalli, G. Madugula and Pedabayalu of Visakhapatnam district. Data on health and hygienic practices such as environmental sanitation (housing, water), frequency of Illness by water, cases of sickness, personal hygiene, use of drugs and drug dependence, causation of disease and their treatment is collected on 2657 subjects drawn randomly from the sample villages following PPS method of sampling.

\section{RESULTS AND DISCUSSION}

Table 1 shows the frequency of illness versus source of drinking water among Khonds. It is observed from the table that the frequency of illness is higher among the tribals consuming stream water when compared to those dependent on well water. Skin diseases such as scabies are observed with a relatively higher frequency among males dependent on stream water $(18.65 \%)$ compared to those drinking well water $(9.89 \%)$. No significant difference is noticed in the incidence of scabies among females consuming either stream or well water. The incidence of malarial fever is observed to be relatively high among males consuming stream water $(6.25 \%)$ when compared to those dependent on well water $(2.28 \%)$. Among females, not much difference is noticed among the subjects consuming stream water $(2.50 \%)$ when compared to those relying on well water $(1.52 \%)$. The incidence of illness caused due to diarrhea, cholera and vomiting is observed to be relatively high among males consuming stream water when compared to those dependent on well water. The incidence of cholera, vomiting, cold and cough, dysentery and typhoid are observed with a relatively higher frequency among females consuming stream water when compared to those drinking well water. Chi-square value calculated between normal and affected subjects consuming well water and stream water is observed to be highly significant. $\left(\chi^{2}=79.59 ; \mathrm{P}>0.001\right)$ Tribe-wise epidemiological statistics and published data on

Table 1: Frequency of illness versus source of drinking water in Khond

\begin{tabular}{|c|c|c|c|c|c|c|}
\hline \multirow[t]{3}{*}{ Type of Illness } & \multirow[t]{3}{*}{ Sample size } & \multirow{3}{*}{$\begin{array}{l}\text { Normal } \\
\text { No. }(\%)\end{array}$} & \multicolumn{4}{|c|}{ Affected* } \\
\hline & & & \multicolumn{2}{|c|}{ Men } & \multicolumn{2}{|c|}{ Women } \\
\hline & & & No. & $(\%)$ & No. & $(\%)$ \\
\hline Stream Water: & 2000 & & & & & \\
\hline a) Scabies & & & 373 & 18.65 & 77 & 3.85 \\
\hline b) Malaria/Fever & & & 125 & 6.25 & 50 & 2.5 \\
\hline c) Diarrhea & & & 85 & 4.25 & 20 & 1 \\
\hline d) Cholera & & & 120 & 6 & 75 & 3.75 \\
\hline e) Vomiting & & & 38 & 1.9 & 18 & 0.9 \\
\hline f) Cold andCough & & & 20 & 1 & 15 & 0.75 \\
\hline g) Dysentery & & & 20 & 1 & 10 & 0.5 \\
\hline h) Typhoid & & & 23 & 1.15 & 8 & 0.4 \\
\hline Sub-total & & $\begin{array}{r}923 \\
(46.15 \%)\end{array}$ & 804 & 40.2 & 273 & 13.65 \\
\hline Well Water: & 657 & & & & & \\
\hline a) Scabies & & & 65 & 9.89 & 25 & 3.8 \\
\hline b) Malaria/Fever & & & 15 & 2.28 & 10 & 1.52 \\
\hline c) Diarrhea & & & 22 & 3.34 & 10 & 1.52 \\
\hline d) Cholera & & & 13 & 1.98 & 8 & 1.2 \\
\hline e) Vomiting & & & 10 & 1.52 & 6 & 0.91 \\
\hline f) Cold andCough & & & 8 & 1.21 & 2 & 0.30 \\
\hline g) Dysentery & & & 8 & 1.21 & 1 & 0.15 \\
\hline h) Typhoid & & & 9 & 1.36 & 2 & 0.30 \\
\hline Sub-total & & $\begin{array}{r}443 \\
(67.42 \%) \\
\end{array}$ & 150 & 19.78 & 63 & 12.78 \\
\hline Total & 2657 & 1366 & 954 & - & 336 & - \\
\hline
\end{tabular}

$* \chi^{2}=79.59 ; \mathrm{P}>0.001$ 
the incidence of illness due to various causes is not available from north coastal Andhra Pradesh. However, a glance at the mortality figures available on rural populations of India indicate several major cause groups such as malaria $(8.7 \%)$, Fevers (7.4\%), Accidents \& Injuries (7.4\%), Snake-bite (7.4\%), Digestive disease (6.6\%), Cough (Disorders of respiratory system) $(20.2 \%)$, Typhoid $(21.3 \%)$, Gastro-enteritis $(24.5 \%)$, Dysentery (20.8\%), Cough (Asthma \& Bronchitis)(43.6\%), Whooping Cough (0.5\%), and Measles (5\%). Similarly, the mortality statistics available on rural populations of Andhra Pradesh also show several major cause groups such as Measles (5\%), Accidents \& Injuries $(8.3 \%)$, Fevers (4.5\%), Digestive disorders $(6.1 \%)$ and cough (13.2\%) (Bhasin, 1994).

Table 2 presents the different causes of sickness and treatment during the last two years of the study (2002-2004). It is observed from the table that majority of the subjects have availed indigenous method of treatment for different types of ailments compared to their preference towards modern methods of treatment. They are observed to use native medicine in a comparatively higher frequency in case of ailments such as measles (100\%), asthma (96.12\%), vomiting (97.20\%), diarrhea $(94.89 \%)$, fever $(95 \%)$, cold $(88.89 \%)$, skin diseases $(84.03 \%)$, wounds and itching
(96.77\%) and snake-bite (97.50\%). Modern medical treatment is observed to be preferred in the case of eye infections $(43.91 \%)$ followed by headache $(41.67 \%)$ and stomach pain $(41.67 \%)$. A comparison of the present data with the available figures (Unpublished) on the incidence of diseases from ITDA, Paderu, Visakhapatnam district, A.P confirms to the condition of high incidence of skin diseases followed by Malaria and respiratory infections.

\section{ACKNOWLEDGEMENTS}

The financial assistance provided by University Grants Commission, New Delhi for the major research project entitled: "Bio-cultural study among some selected primitive tribal groups of Andhra Pradesh" (F-5-367/2003(MRP) is gratefully acknowledged.

\section{REFERENCES}

Basu, A.: Anthropological approach in tribal health, pp. 131-142, In: Tribal Demography and development in North-east India. A. Bose, T. Nangbri and N. Kumar (Eds.). B.R.Publishing Corporation, Delhi (1990)

Basu, S.K.: Genetics, socio-cultural and health care among tribal groups of Jagadalpur and Konta Tehsils of Bastar district, M.P. pp. 87-105. In: Anthropology,

Table 2: Frequency of sickness and the preference of treatment

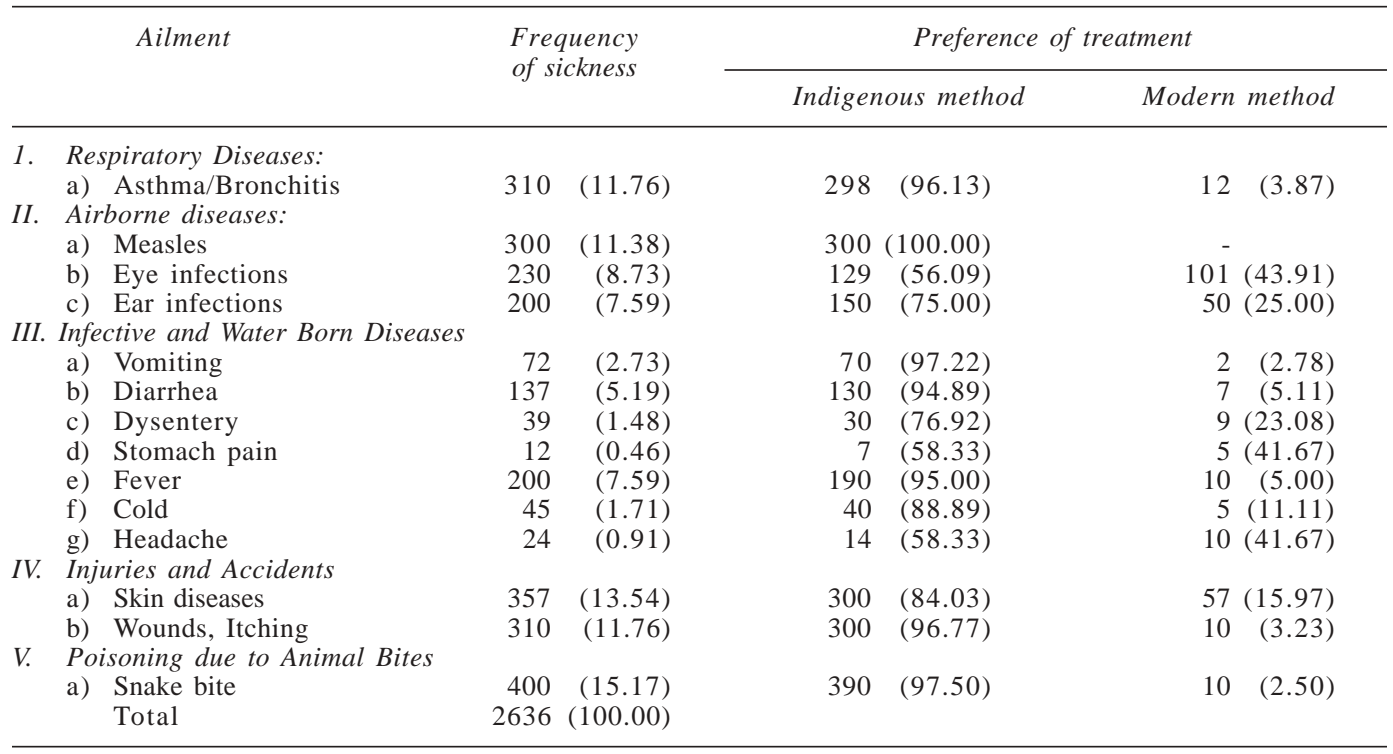

(Figures in parenthesis indicates percentage) 
Development and Nation Building. A.K.Kalla and K.S.Singh (Eds.). Concept Publishing Company, New Delhi (1986)

Behura, N.K.: Health culture, ethno-medicine and modern medical services, J. Anthrop. Surv. India, 52: 27-67 (2003).

Bhasin,V.: Habitat, Habitation and Health in the Himalayas: a Comparative Study of the People of Sikkim and the Gaddis of Himachal Pradesh . KamlaRaj Enterprises, Delhi (1990)

Bhasin,V.: People, Health and Disease :The Indian Scenario. Kamla- Raj enterprises, Delhi (1994).

Chaudhury, B.: Social and Cultural aspects of health. Journal of Social and Economic Studies, 39: 379388 (1986)

Mahapatra, L.K. and Das, J.: Nutritional ecosystems of Orissa tribals. In: Cultural and Environmental
Dimensions of Health. B.Chaudhuri (Eds.) InterIndia Publications, New Delhi (1990)

Majhi , J and Sharma B.V.: Ethno-medical practitioners and their clients among the Khonds, Man in India, 84(1and2): 99-107 (2004).

Raj Pramukh, K.E.: Tribal health in Visakhapatnam district of A.P. J.Hum.Ecol., 9(2): 191-193 (1998)

Rizvi, S.N.H.: Health practices of the Jaunsaris: A sociocultural analysis. pp.223-246, In: Tribal Health: Socio-cultural Dimensions, B. Choudhury (Ed.). Inter-India Publications, New Delhi (1986).

Swain, S, Jena, S.C. and Singh, P.: Morbidity status of the Kondh tribes of Phulbani (Orissa), pp.177-191. In : Cultural and Environmental Dimensions of Health. B.Chaudhuri (Ed.) Inter- India Publications, New Delhi (1990).

W.H.O.: Constitution. WHO, Geneva (1946). 